pp. $293-317$; Aladenic Press

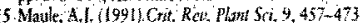

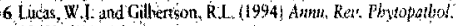
$32,387-411$

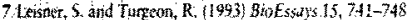

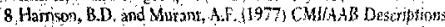
iof Plent Vinses (Avi: 185) Association of Appled Biologists

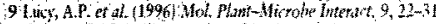

10 Kassanis, B, Russell, G, E and Whire R.F. (1978).

Prytotiathol. Z $91,76-79$

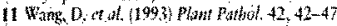

12 Wang D and Mate A . . (19924. Gen. Virn). $73.1615-1620$

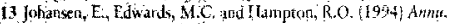

Revi. Phyotuthil $32 ; 36 ;-386$

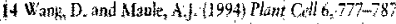

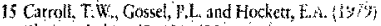

plyoputiatigy $69,43 !-433$

16 Sisler,W.W. and Timina R.G. (1956) Flant Dis, Rop, 40 . $\int 106-1103$

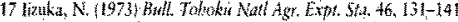

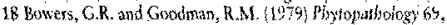
569,572

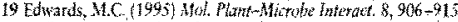

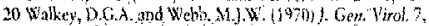
$159-166$

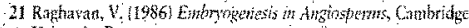
Linicersity Press

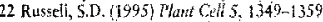

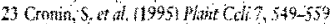

24 Copper, De $(1938)$ bot $032,100,12\}-132$

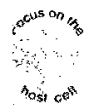

\title{
Cohabitation of Leishmania
} amazonensis and Coxiella burnetii

\section{Michel Rabinovitch and Patricia Sampaio Tavares Veras}

$\mathrm{C}$ Tellulair natbogens often impose intriguing varinormal postphagocytic events and control the fusion comperence of the vacuoles they occupy ${ }^{1}$. Parasite containing vacuoles can display phenonypes that ressrict or permit fusion. but the pathogen signals tnat wictate vacuolar phenotypes in most cases have niot been identified

Cells dually infecred with dif ferent prokaryotic and/or etkaryotic pathogens have rarely been reported in the literature (Box 1). We found thar, by a suitable choice of organisms, it
Intracellular pathogens customize the composition and function of the vacuoles they occupy, and can arrest or distor: vacuolar maturation. In doubly infectied cells, vacuoles that contain two different parasites can be used to test for exclusionary mechanisms, for expression of vacuolar phenotypes that permir or restrict fusion, and for the survival of pathogens targeted to an unustual cellular comparment.

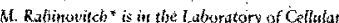

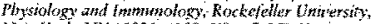
Neiv York. NY 10021-639\%:USA,P.S.T. Vords in

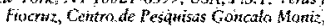
CEp $40295-401$, Satiador, BA, Brazil "/axt +12123278875 ,

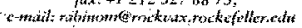

by molecules released by the pathogens.

Coniolla burneti is a highly infecrive, spore-forming bacrerium transmitted by aerosol from animals to man ${ }^{5}$. This organism, not yet grown in a pure culrure, was responsible tor outbreaks of $\mathrm{Q}$ fever later raced to infected sheep brought into the laboratory. We have used an attcnuated phasc. II strain of $C$. burnetii, derived by sequential transfer of infective bacteria in avian cggs. Phase if organisms infect cells in culture but are nor virulent for labora. tory animals, nor do they revert to phase I. Nevertheless, safery is posible to construct 'doubly infected vacuoles' that, at least temporarily, shelter two different organisms. The first doubly infected vacuotes contaned the rickertsia Coxiella bumetit and the protozoan flagellate Leish maria amazonensis, organisms that normally live within fusion-permissive vacuoles (Fig. 1), We also obtained doubly infected vactoles in which $C$. butneti was associated with Trypanosoma cruzi or with Mycobacterixim duium.

\section{Fuston prone partner vacules}

Coxiella bumetii and $L$ : amazonensis both inhabit fit sion-permissive, prelysosomal or phagolysosome like vacuoles $s^{5,4}$ It ts not known if fusion of these vacubles with lysosomes is tequited for survival or is upregulaced regulations require level 3 containment for both phases ism as the Sleeping Beaury" of intracellular infection. Indeed, arwotg the $652 \mathrm{C}$. farmetit entries in Medine in the last 30 years, only 24 deal, and often peripherally, with the biology of $\dot{C}$-burnetii-infected cells.

Leishmartia amazonensis and $C$. burnetii have com mon features that make them useful parners in dually infecied colls".6. (1) Different cell types can be efficienty infected in vitro and develop large vacuoles contain ing numerous organisms; (2) Infected; non-replicating cells survive for several days or more, and cell lines can be persistently infeced. (3) The organisms thrive withit actidied hydrolase -rich yacuoles that avidly fuse with secondary lysosomes and with certain incoming of C. bumatit; a stricture that helped to keep the organ- 
phagocytic vacuoles. vacuoles cortaining L: amazon. ensis or C. burnetii appear to function as lysosomal traps; in hoth cases, host cells are depleted of secondany lysosomes ${ }^{7}$. Vacuoles containing L, amazonensis, because they stain for the GTP-binding proteins Rab7 and Rab9, are thought to be prelysosomes": Recently, however, Rab7 was found a subpopulation of lysosomes in normal cells ${ }^{11}$. It is likely that L.-umazonersis-containing vacuoles enlarge by fusion with endocytic vesicles without balanced membrane retrieval. tusion betweer $L$-amazonensis-containing vacuoles has been recorded, albeit uncammonly, in time-lapse novit sequence ef infeted macrophage cul tures ( $\boldsymbol{A}_{\text {. }}$ Pouchelct, pers, commun.).

Far less is known about C.-burnetit containing vacuoles. The membranes of these vacuoles stain prominently for $\mathrm{CD}_{63}$, a lysosomal marker, but not for transferrin receptors, found in early endosomes ( $\mathrm{S}$. Paul, pers, commun.). In contrast to L. -amazonensis. containing vacuoles, the large vacuoles containing $C$. burnetii appear to arise by the fusion of smaller vacuotes ${ }^{1 !}$.

\section{Games vacuoles play with inert partinles}

Our cohabitation experiments came as a sequel to studies of the kinetics and selectivity of transfer of inert particles to vacuoles occupied by $L$ : amazonensis or C. bumetii ${ }^{12,13}$. Fusion was inferred by observing the colocalization of particles and parasites. We found that $L$, amazonensis-containing vacuoles in macrophages fuse with phagosomes containing yeastderived particles, but, tather surpris ingly, not with inmunoglobulin-G coated erythrocytes or latex beads: Fusion is probably dictated by the nature of the receptors that recognize the particfes, the signals being encoded in the receptor's cy tosolic domants; the persistence of the signals may depend on the rate of degradation of ligands and receptors in the vacuolar environment ${ }^{2}$ - Vacuoles containing $L$. amazonensis in Chinese hamster ovary (CHO) cells also only fuse with some rypes of incoming vacuoles ${ }^{13}$. In conuast, C-burnetii-contaning vacuoles in CHO cells are promiscuous, and fuse efficiently with the phagosomes tested ${ }^{13}$

\section{From inert particles to living parasites}

As C.-burntiz-containing vacuoles appeared to-be particularly prone to fusion, we chose them as recipient vacuoles $\mathrm{CHO}$ or other cells were Microbiology
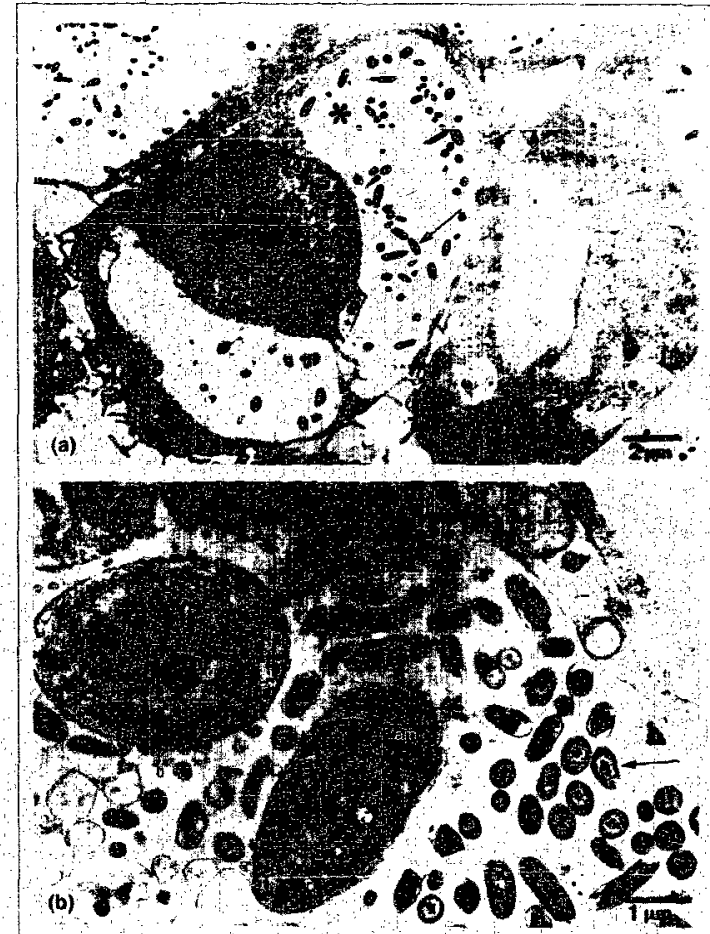

Fig. 1. Uitrastructure of Chinese hamster ovary cells (a) infected for 5 days with coxiefla burnetil alone and (b) infected for 3 days with $C$. burrietii. superinferted with Leishmania amazonensis, and fixed 2 days bater. The stars mark the lumer of the coxiella-containing vacuoles. in. divioual Coxiella bacteria are marked by arows and am indicates aj amastigote of Leishmatria. Electron micrograph is courtesy of C. Dauget (Pasteur Iristitute. Patis, France). Scale ba $=2 \mu \mathrm{m}$ in (a) and $1 \mathrm{\mu m}$ in (b). Reprnduced from Ref. 14 with perimission from the American Society for 
infected with the bacteria, and 2 or 3 d later, when more than $90 \%$ sported large C. bumctii-rich vacuoles, calls were superinfected with $t$, cintatoneisis amastigores, and fixel ar different times for increscopic observation. Large vactioles that contained both $C$ burnetin and $L$. denatomentsis were discrved $6 \mathrm{~h}$ atter superiatection. and the numbers of amastigores increased with times.

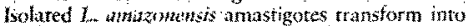
fully flagellated morile promastigites when shifted to lower temperarures. When doubly infected cells were placed at $25^{\circ} \mathrm{C}$ for $24-48 \mathrm{~h}$, amastigotes in the mixted vacuoles transformed into promastigetes, which, by whipping their flagella, swirled $\mathrm{C}$. burnetis within the shared racuoles. Furthermore, essentally all the amastigotes were killed by k-leucyl-O-nethyl ester, to which armastigotes, but tiot bost cells of promastigotes, are vuluerthet? The evidence indicates that $L_{1}$ amazom ensts can remain alve for several days within the mixed vacuoles.

It is cicarly jenportant to distinguish morphological colocalization of rwo organisms - the outcome of vacuolar fusion - from their cohabitacion, which reguires proot of at least remporary surival and even berter, multiplication of the two partuters: Whereas the former has been achicyed, the later is sall incomplete, as precise counts of viable C. burnetî are not easily obtaned:

\section{C. bumetif or $L$. amazonensis vacuoles as hosts for other angimisins}

Intective foms of $T$, cruzi nomally ener cells via newly assembled lysosonat compartments trom whicl parasites exit to the cytosol and multiply as amastigotes ${ }^{16}$. When C-burnetit-infected cells were supetintected with T. chuzi tissue culure trypornastigotes, flagellates reminiscent of the Loch Ness monster circled incessanily: within the adopive C.-bumetii-infected vacuoles, as docimented in video sequences. The vacuoles also contained tumerous amastigote-like forms. The inplication is that in the superinfected cells, the flagellats do nor enter the cytosol, bitr transform into amastigore-like forms within vacuoles occupied by $C$ burrenit [Rabinovitch, M etal. (1995) Memorias Instituto

\section{Questions for future research}

- Can the contrasting fusion efficiency and selectivity of vacuoles containing either coxiella bumeti or Leishmania amazonensis be accounted for by differences in the composition of the respec. tive vacuolar memoranes?

- Are similar mechanisms used for hansotypic and heterotypic firsion of vacuofes that contain $C_{n}$ bumetir? Does the homptyptc fusion that takes place in the couse of cellutar infection, with $C$, bumeti account for the efficient heterotypic fusion of $C$, tumeti-contain ing vacuoles?

- Does C, bumetif secrete fusion enhancing factors? if so, could these factors modify the selectivity of vacuolar fusion? Would they act within the vacuoles of in the cycosol? Alternatively, does C. Lumethi induce host celis to make fusigenic faciors?

- Given that $C_{+}$-bumeti-containing vacuoles display hsosomal fea-

tures not found in vacuoles that shelter Mycobacterium avium, what would be the features of dioubly infected vacuoles containing both organisms?
Oswoldo Craz 90 (Suppl. 1), 5-6). This hypothesis is sipported thy the finding that low mediun pH can cigger the transformatim of isclated T. cont trypo-" mastigetes into amastigote-like fornst?

Paradigns of testricted vacus fusion are provided by Mycobacteritm twberchlosis and Mycolyacteriatt" "fritum, which lodge in maturation blocked unacidified vacules that way fuse with sndosomes, bur not with

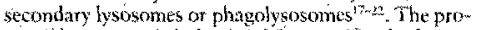
posil that ammonta is the signial that specifies rhe fusionrestricted phenotype gained support from the finding thar M. fiberculosis secretes gluramint synthetase into the vacuolar lumer:"s.

Ultrastrtictural studies petformed in association with Chantal de Chastellier also denonstrate that $M$, aniwm and C. burnetit can efficiently colocalize in vacuoles of doubly intected mactophages; furmemore, both organisms are structurally well preserved in the doubly infected wacuoles: In contrast, colocalization of $M_{\text {. avium }}$ and $L$, antazonensis was leśs frequently observed $d^{*-}$. Althongh $C_{\text {- }}$-bumotiz contaning vacuoles have features of phagolysosomes they have not yet been adequately characterized. Endosome-like wacuoles containing cationized ferritin eagerly fuse with Mycobacterikmmicroticontaining vacuoles formed in mactophages in the presence of ammonium chloride ${ }^{\text {" }}$. Consequently, it nay be fruitul to compare the compositional and functional features of these no rypes of vacuoles.

\section{The 100 vaculos guestion}

Parasite colocalization and evenual cohabitation ic. quires movenent, docking and fusion of vacuoles enclosing different parasites; fusing vacuoles may or may nor te phenorypically similar. The biochemical and molecular mechanisms that underlie these events are unknown. $A$ basic question that needs to be answered, case by case, is: does fusion of parasite vactioles and its regularion by parasitc-derived signals involve 'normal' fusion pathways as defined for vacuoles that contain nonviriblent organisms or particles?

The answers should come from the convergence of independent areas of research. (1) Work from differ ent laboratories has defined highly conserved mechanisms for budding and fusion of small vesictes involved in intracelluar protein transport, exocytosis and endovytosis in differtil eukaryutic cells. Fur eximpie, the ATPase NSF (N+thylmalemide-sensitive factor), SNAPS soluble NSF attachment proteins), VSNARES and ISNARES (SNAP receptors), Rab proteins qguanosinetriphosphate binding proteins), ARFs (adenosine diphosphate-ribosylation factors) and many other pro teins involved in vesiche recognition, docking and fusion have beencharacterized, their genes cloned, and in sone cases expressed and muated ${ }^{2526}$. The mechanisms that involve these protein's provide a detailed backdrop against which fusion of normal and pathogen-containing vacuoles can be rested: (2) rompositional changes of membrane and contenrs of normal phagosones lave heen clicidated in situ and in phagosome-enriched celi fractions ${ }^{2}$ (3) $^{2}$ Fusion of endosomes with phagosmes comaining killed bacteria has been reconstituted in utaro and shown to display requirements common 
to those known for the endocytic and secretory path- way $\mathrm{s}^{27}: 4 \mathrm{Ca}^{2-4}$ and annexin-dependent mechanism for phagosome-endosome fusion has also been revealed"s? (4) Vacuoles enclosing Mycobacteria or Leishmania species have been isolated from infected macrophages and their ultrastructural, antigenic and biochemical characterization initiated ${ }^{\text {! }}$. Advaties car also be $\mathrm{ex}$ pected from less in asive in situ methodology, irvolving reversible cell permeabilization, microinjection and genetically modified host cells that hyperexpress or do not express proteins, involved in normal vesicle fusion. Collaboration berween cell biologiots and parasitologists is needed' so as ro arply the inpressiol advancics in research on membrane trafficking to parasite-infected $\because i l s$. There is a need for better nonmic roscopic methodology te measure fusion hetween phagocytic vacuoles. Fusion between endosomes and phagosomes has been siudied by measuring the formation of complexes formed when vacuole populations containing; for instance, a biotinylated particle, are coincubated wits: another set of vacuoles containing an aridin-derivatizis molecular ligand ${ }^{23}$. This strategy does not work when both vacuole populations contain particles, as contact of the particles within fused vacuoles does not nocssarily take place.

\section{Why doubly infected vacuoles?}

Although vacuoles containing two different parasiter may not exist in nature, artificially constructed dotbly infected vacuoles may have some uses.

(1) Doubly infected vacuoles can test for compat ibil ity of two different pathogens within a common intracellular microenvironment. Did exclusionary mechanisms evolve to reduce pathogen competition for growth factors or to prevent undesirable genetic exchanges: Can toxic products from, or nutrient depletion by one organism affect the survival of another in the same vacuole? Alternatively, can growth enhancement occur by some sort of complementation between pathogens?

(2) Compositional and functional features of doubly infected vacuoles can provide information regarding dominance of parasite sigmals that sjecify different vacuolar phenotypes.

(3) Colocalization in racuoles can entrap pathogens in unusual locations and, therefore, can implicitly test for pathogen survival in potentially stressing microenvironments.

\section{Acknowledgennents}

Most of the studies summarized here were performed at the lasstut Pasteur, Paris, and LRA 361 of the CNRS, France and suppotted by Institur Pasteur an CNRS. Cutrent work by M R is supported by NIH grant AI 22616 to Dr G. Kaplan. We thank D.G. Russell and D.L. Clemens for constructive onmathes M.R. dedicares this paper ou the niemony of Rofert Fawe [1930-1995]

\footnotetext{
Réferences

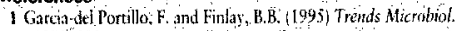
3, $373-380$

2 Wether, Y a d (1993) infect Intmon 61, $1596: 1598$

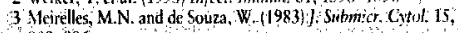
$889-1396$

4 Black; C.M el al (1090) I Exp. Med 172, $977-980$
}

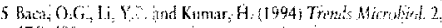
$476-48$ !

6 Rusel, DG, 17-45, Trends Cell Biol, 5, 25-129

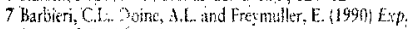
Purasitol. $71.18-228$

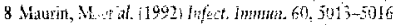

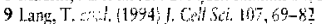

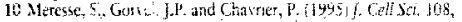
$3349-8: 28$

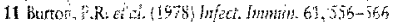

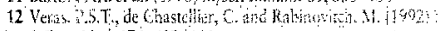
1. Ext: Med. $176,639+646$

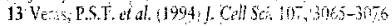

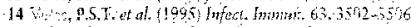

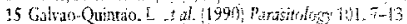

16 Andrews $\mathrm{V}$ W. $199 \mathrm{~s}$ trends Coll Biol $5,1,33-13$.

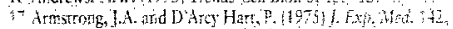
$1-16$

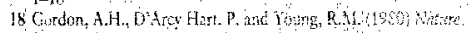
$286,79-80$

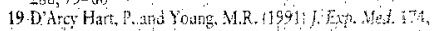
$881-889$

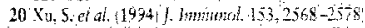

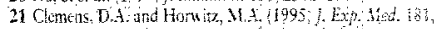
$2,5(-7)$

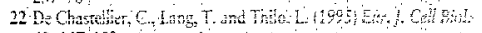
$68,167-182$

23 Hart, G. Clemens, D.L and Horwe, H.A. 1994 Proc But

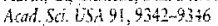

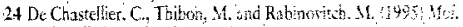
Biol. Cell 6 Suppl abst 634

25 Rothnati, ]. 1994) Rinme $572,55-63$

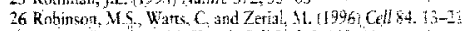

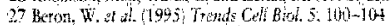

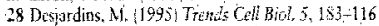

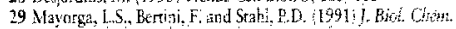
$266,6591-6517$

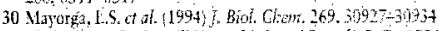

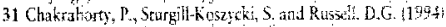
Methots Crif Btol t5. 261-276:

\section{Reference added in pronf}

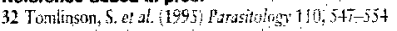

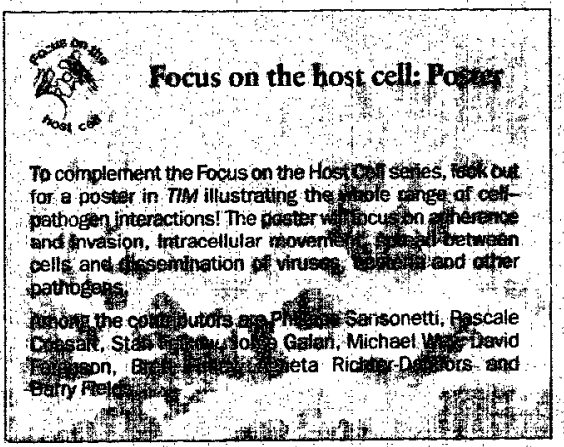

